ates." The European Union is notoriously bureaucratic, and grasping these programs is not easy. A further complication is that each member country has considerable latitude in how it implements the EU-wide programs. The authors have done a good job of putting the most important information in readable tables, with many footnotes in small print for readers interested in more details. (North American readers who are unfamiliar with European regulations, agricultural programs, and institutions may still have a bit of difficulty, although they will be helped by a list of acronyms and an extensive list of references. Conveniently, too, all currencies have been converted to European Currency Units-now the Euro-even for non-member nations.)

A second value of the book is that it points out many of the choices that must be made in going from a general policy, such as support payments for organic farming for their environmental value, to specific programs. These choices can be seen both by scanning the country-bycountry tables, and from examples discussed within the text. For example, if a farm qualifies for both the organic component of the agri-environmental support program and other components, should it receive both payments? (Some countries require a choice of one or the other, others allow both, while still others also allow both, but at a reduced rate.) Should farmers be allowed to convert only part of a farm to organic? (Most countries allow it, but a few don't.) Should payments be made just for conversion, or also for maintaining organic practices? (Most EU members do both.)

Finally, for North American readers, the book should have considerable inspirational value. The numbers and the tables are powerful evidence of how much can be done to encourage organic farming if the political will is there. The most impressive part of the picture that emerges from this book is that the official support for organic farming in Europe is no longer merely a response to the demands of a particular group-organic farmers and consumers. Rather, it has become part of the larger agricultural policy picture, with promotion of organic farming now seen as an important strategy for steering Europe's agriculture in economically and environmentally desirable directions.

Of course, the agricultures of Western Europe and North America differ in some important structural and historical aspects. But the cultures, technologies, and economies of the two regions have much in common, and they face similar environmental and rural economic problems. Therefore, looking at Europe's support of organic farming, it is fair to ask the obvious question: "If they can do it, why can't we?"

William Lockeretz, School of Nutrition Science and Policy, Tufts University, Medford, MA 02155.

\title{
WALLACE CENTER NEWS
}

\section{Agriculture Policy Project Develops Draft Recommendations for Seven Major Issues}

The Wallace Center's Agriculture Policy Project, a 5-year project started in 1997 and funded primarily by the W.K. Kellogg Foundation, has just completed its draft national policy recommendations. The recommendations were based on the results of 16 local, regional, and national policy sessions held throughout the United States and developed by a team of 9 policy advisors who have been working with the project staff over the last 6 months. The recommendations cover 7 major agricultural and food issues of concern to participants in the 16 sites, including: marketing; farmland preservation; contract markets; rural development; water and air quality; research, education and training in alternative farming systems; and access to capital and credit.

The draft recommendations have not been made public yet. They will first go through a "feedback loop" process in which they will be distributed to approximately 180 of the project's participants for comment. The recommendations will be finalized by March 2001, after a national meeting of participants. For more information, contact Lydia Oberholtzer, Henry A. Wallace Center for Agricultural and Environmental Policy, Winrock International, 1621 N. Kent St., Suite 1200 , Arlington, VA 22209; (703) 525-9430 Ext. 664; email, loberholtzer@winrock.org.

\section{Historic USDA Research Center Named for Henry A. Wallace}

A major historic USDA research center in Maryland has been named for Henry A. Wallace, former U.S. Vice President and Secretary of Agriculture. The Henry A. Wallace Beltsville Agricultural Research Center, part of the Agricultural Research Service, is a 6,500-acre scientific facility that is one of the largest agricultural research centers in the world. Speak- ing at the ceremony were U.S. Rep. Steny Hoyer of Maryland, former Senator Dale Bumpers of Arkansas, former Senator John Culver of Iowa, USDA Secretary Dan Glickman, and Jean Wallace Douglas, Henry A. Wallace's daughter, Honorary President of the former Henry A. Wallace Institute for Alternative Agriculture, and long-time supporter of the Wallace Center's work.

"Henry A. Wallace changed the face of American agriculture during his career as a scientist and as Secretary of Agriculture," Secretary Glickman said. "Wallace was committed to the idea that science is our best hope for sustaining agriculture and preserving the environment."

The USDA described Wallace as "a corn geneticist, an agricultural economist, and a vigorous advocate of soil conservation and ecology. Wallace believed scientific research was the best way to advance agriculture and maintain the quality of soil and the environment as a whole."

American Journal of Alternative Agriculture 